\title{
TEORIA MARXISTA, TEORIA CRÍTICA E EDUCAÇÃO
}

\author{
TEORÍA MARXISTA, TEORÍA CRÍTICA Y EDUCACIÓN
}

MARXIST THEORY, CRITICAL THEORY AND EDUCATION

Jessica Sampaio FIORINI ${ }^{1}$

RESUMO: O presente artigo tem como objetivo apresentar considerações acerca da Teoria Crítica, tecendo reflexões para a educação a partir Theodor Adorno. Para tanto, a partir do levantamento bibliográfico sobre o assunto, buscou-se por meio da leitura de materiais bibliográficos exposições de diferentes autores/as acerca do tema. Assim, são abordados alguns conceitos referentes à Teoria Marxista, a qual influenciou a elaboração da Teoria Crítica, partindo das considerações de autores como Pedro Demo e Augusto Triviños. Ademais, neste artigo, apresenta-se um histórico quanto à Teoria Crítica, de forma sucinta. Por fim, são apresentadas as ideias trazidas por Theodor Adorno, um dos expoentes da Teoria Crítica em relação à educação, suscitando algumas discussões para o campo educacional.

PALAVRAS-CHAVE: Teoria crítica. Educação. Theodor Adorno.

RESUMEN: El presente artículo tiene como objetivo presentar consideraciones acerca de la Teoría Crítica, tejiendo reflexiones para la educación conforme a Theodor Adorno. Para ello, a partir del levantamiento bibliográfico sobre el asunto, se buscó por medio de la lectura de materiales bibliográficos exposiciones de diferentes autores / as sobre el tema. Así, se abordan algunos conceptos referentes a la Teoría Marxista, la cual influenció la elaboración de la Teoría Crítica, partiendo de las consideraciones de autores como Pedro Demo y Augusto Triviños. Además, en este artículo, se presenta un histórico en cuanto a la Teoría Crítica, de forma sucinta. Por último, se presentan las ideas traídas por Theodor Adorno, uno de los exponentes de la Teoría Crítica en relación a la educación, suscitando algunas discusiones para el campo educativo.

PALABRAS CLAVE: Teoría crítica. Educación. Theodor Adorno.

ABSTRACT: The objective of the present article is to present considerations about of Critical Theory, weaving reflections for the education from Theodor Adorno. To do so, based on the bibliographical survey on the subject, we searched through the reading of bibliographical material expositions of different authors about the theme. Thus, some concepts referring to the Marxist Theory are discussed, which influenced the elaboration of the Critical Theory, starting from the considerations of authors like Pedro Demo and Augusto Triviños. In addition, in this article, a history is presented on the Critical Theory, in a succinct way. Finally, the ideas brought by Theodor Adorno, one of the exponents of the

1 Secretaria Municipal de Educação - (SME), Marília - SP - Brasil. Professora de EMEF. ORCID <https://orcid.org/0000-0001-5169-0820>. E-mail: jessicafiorini.unesp@ gmail.com.

Doxa: Rev. Bras. Psico. e Educ., Araraquara, v. 20, n. 2, p. 196-211, jul./dez., 2018. 
Critical Theory in relation to education, are presented, provoking some discussions for the educational field.

KEYWORDS: Critical theory. Education. Theodor Adorno.

\section{Introdução}

O presente artigo resultou do interesse em conhecer alguns dos pressupostos da Teoria Crítica e sua contribuição para a educação, tendo como conjetura a de que "A Teoria Crítica se revela um instrumento importante para a análise educativa por nos apresentar o processo histórico de constituição da razão em sua dialética.” (BUENO, 2003, p. 23).

Dessa forma, a partir do objetivo de apresentar considerações acerca da Teoria Crítica, tecendo reflexões para a educação a partir Theodor Adorno, sem a pretensão de esgotar nenhum dos temas abordados, o presente artigo apresenta algumas discussões importantes para a explanação pretendida. Assim, em Teoria marxista do conhecimento: breves considerações a partir de Augusto Trivinõs e Pedro Demo, bem como em Um pouco de história a luz do referencial marxista, são abordados alguns conceitos referentes à Teoria Marxista, a qual influenciou a elaboração da Teoria Crítica. Em Teoria crítica: síntese, é apresentado um histórico, de forma sucinta, quanto à Teoria Crítica. Posteriormente, são apresentadas as ideias trazidas por Theodor Adorno, um dos expoentes da Teoria Crítica em relação à educação, em: Por que pensar a educação?

Para o alcance dos objetivos supracitados, foi realizada uma pesquisa desenvolvida mediante a revisão bibliográfica, quando buscou-se, por meio da leitura de materiais bibliográficos, as contribuições de diferentes autores/as acerca do tema.

A saber, este artigo é o resultado do aproveitamento da disciplina intitulada Teoria Crítica: racionalidade comunicativa e reconhecimento social, do Programa de PósGraduação em Ciências Sociais, oferecido pela UNESP, disciplina essa ministrada pelos professores Aluísio Schumacher e José Geraldo Poker.

\section{Teoria marxista do conhecimento: breves considerações a partir de Augusto Trivinõs e Pedro Demo}

Conforme Trivinõs (1987, p. 49), “Karl Marx (1818-1883), ao fundar a doutrina marxista na década de 1840 revolucionou o pensamento filosófico, especialmente pelas conotações políticas explícitas nas suas idéias [...]”. O marxismo, assim como viera a ser 
chamada a corrente filosófica influenciada pelas ideias de Marx, teve quatro fases ao longo da História. A primeira é representada pelo próprio pensador; a segunda, pelo trabalho feito conjuntamente ente Marx e Engels; a terceira, marcada pelas considerações de Lênin e por último a contemporânea, na qual consideram-se as tendências soviéticas e chinesas. (TRIVIÑOS, 1987).

Segundo o autor, a concepção de mundo e a forma como compreendê-lo pelo enfoque dialético, teve suas bases no pensamento de Hegel, pelo qual Marx sofreu grande influência, embora tenha rejeitado o cunho idealista do pensamento hegeliano, pois é em Hegel que se encontra destaque ao caráter dinâmico, processual, mutável do mundo e da história. Dessa forma, sua concepção é baseada no materialismo filosófico. Para Triviños: "O Materialismo Filosófico apóia-se nas conclusões da ciência para explicar o mundo, o homem e a vida." (TRIVIÑOS, 1987, p. 21).

Assim, o materialismo dialético de Marx e Engels, fora desenvolvido com base em princípios hegelianos, exceto pelo fato de conter também princípios advindos da filosofia materialista (visão de mundo apoiada na ciência), além de se basear na visão dialética da realidade. Conforme apresenta Triviños (1987, p. 51 grifos do autor): "O materialismo dialético é a base filosófica do marxismo e como tal realiza a tentativa de buscar explicações coerentes, lógicas e racionais para os fenômenos da natureza, da sociedade e do pensamento.".

$\mathrm{O}$ autor aponta ainda, as principais ideias que caracterizariam o conceito de materialismo dialético: "Resumidamente, podemos dizer que o materialismo dialético reconhece como essência do mundo a matéria que, de acordo com as leis do movimento, se transforma, que a matéria é anterior à consciência e que a realidade objetiva e suas leis são cognoscíveis." (TRIVIÑOS, 1987, p. 23).

Além dos princípios já citados, quais sejam a matéria e a dialética, o materialismo dialético avalia a prática social como sendo um critério a ser considerado na teoria do conhecimento: "Desta maneira, as verdades científicas em geral, significam graus de conhecimento, limitados pela história [...] este relativismo não significa reconhecer a incapacidade de o ser humano chegar a possuir a verdade." (TRIVIÑOS, 1987, p. 51).

Por último, o materialismo histórico é uma concepção científica filosófica que tem como enfoque a sociedade. Conforme o autor: "O materialismo histórico é a ciência filosófica do marxismo que estuda as leis sociológicas que caracterizam a vida da sociedade, de sua evolução histórica e da prática social dos homens, no desenvolvimento da humanidade." (TRIVIÑOS, 1987, p. 51, grifos do autor). Se antes do marxismo, os fenômenos sociais eram explicados por concepções idealistas, o materialismo histórico trouxe o estudo sobre a 
sociedade considerando como categoria de análise, dentre outras, as relações de produção e a formação social e econômica. (TRIVIÑOS, 1987).

Assim, a dialética teve influência e contribuição de Hegel, o qual ajudou a consolidar no conceito, o caráter mutável e dinâmico do mundo. E é baseando-se nesse conceito hegeliano que Marx e Engels, pensaram o materialismo dialético. "Neste sentido, o materialismo dialético não é só uma dimensão ontológica, mas também gnosiológica, já que estuda o conhecimento e a teoria do conhecimento como expressões históricas." (TRIVIÑOS, 1987 , p. 53).

Conforme Demo (1995), a formação social é dotada de uma organização da qual o conflito social é inerente e promotor da dinâmica social, que caracteriza a superação de uma dada situação, a qual já fora a superação de uma situação anterior e a qual certamente será superada por meio do conflito social. Tal superação não é fruto de fenômenos metafísicos, mas do antagonismo parte da sociedade que por ser dinâmica em sua transformação, é histórica. Nas palavras do autor: “[...] toda formação social é suficientemente contraditória, para ser historicamente superável.” (DEMO, 1995, p. 89).

Para Demo (1995), a antítese é um conceito básico da dialética: “Quer dizer que toda realidade social gera, por dinâmica interna própria, seu contrário, ou as condições objetivas e subjetivas para sua superação. A antítese alimenta-se da estrutura do conflito social, tomandose também marca estrutural da história, que caminha por antíteses." (DEMO, 1995, p. 91).

Grosso modo, o conceito pode ser exemplificado da seguinte forma: a realidade social, composta por uma organização social específica e institucionalizada, é a tese. Entretanto, toda formação social é contraditória e por sê-la, apresenta sua síntese, a qual seria a superação da tese, ou, da formação social inicial. Esta síntese, por sua vez, transforma-se em uma nova tese que também sofrerá a mesma dinâmica. $\mathrm{O}$ processo entre a tese e a síntese é caracterizado pela antítese, que é a própria contradição: "No movimento antitético está o signo de mudança." (DEMO, 1995, p. 92). O autor ressalta ainda que a antítese pode ser radical ao transformar totalmente a estrutura da formação social inicial, ou apenas pode promover uma reforma da realidade primeira.

Demo (1995) assinala que a contradição faz parte da formação social histórica, visto que as posições divergente dentro de um mesmo contexto social, existe pela necessidade que uma parte tem da outra no conflito, o que designa o conceito dialético de unidade de contrários, dito de outra maneira: "A 'marginalização social' é fenômeno dinâmico de inclusão, porque a acumulação espoliativa da riqueza necessita da pobreza oprimida." (DEMO, 1995, p. 93, grifos do autor). 
Demo (1995), apresenta condições naturais e sociais, o que a fazem ser objetiva e subjetiva. "A realidade natural é 'determinada', dentro do esquema rígido de causa e efeito, pelo que é possível descobrir leis de sua constituição, sempre independentes da vontade humana." (DEMO, 1995, p. 94). Quanto à realidade social, Demo (1995, p. 94) afirma: "A realidade social não é determinada, mas 'condicionada' o que permite atribuir-lhe maneiras típicas, tendências, regulares do seu acontecer. É previsível nesta medida, bem como planejável e manipulável, ou seja: pode em parte ser feita pelo homem.”.

De acordo com o autor (1995, p. 94): “Consideram-se condições objetivas aquelas dadas externamente ao homem, ou dadas sem sua opção própria.”. Por outro lado, "Consideram-se condições subjetivas aquelas dependentes da opção humana, a capacidade de construir a história em parte, em parte no contexto das condições objetivas." (DEMO, 1995, p. 94).

Para a transformação da realidade, Demo (1995) assevera que é de suma importância, dentro de uma dada condição objetiva, a existência do ser político, que não aceita a condição de ser expectador da realidade. Dessa forma, a subjetividade se faz a base da transformação da realidade e o ator político constroi a história no contexto objetivo:

A existência objetiva da pobreza não faz sozinha o revolucionário. Para tanto, é mister construir a consciência crítica e autocrítica, capaz de perceber pobreza, para além de condições objetivas, como injustiça social, como opressão e, a partir daí, construir caminho próprio de conquista da autopromoção. (DEMO, 1995, p. 96).

O papel exercido pelo ator político, na visão marxista, é o papel do partido político. Porém, atentando-se a essência dos conceitos, em suma, a mudança da história é caracterizada por uma dada realidade objetiva, a qual é passível de mudança a partir da ação política exercida sobre a realidade objetiva.

Outro conceito base na teoria marxista, refere-se à unidade de contrários, a qual considera que a formação social é composta por partes polarizadas que formam um todo de necessidade e de repulsa. Não pode ser considerada uma unidade contraditória porque o termo significaria extinguir a outra parte, quando na verdade, ao mesmo tempo em que se afastam, se necessitam. Por outro lado, a contradição histórica tem relação com o conflito social.

A unidade de contrários, é a chave da mudança, visto que numa dada situação, em que há uma ideologia dominante, há certamente, uma contra-ideologia que, por sua vez, promove a reação que impulsiona a mudança da realidade objetiva, e isso, conforme a posição do autor, 
é o que há de mais produtivo dentro de um sistema participativo, já o consenso, não promove mobilização. (DEMO, 1995).

\section{Um pouco de história a luz do referencial marxista}

Com a decadência do feudalismo e o início das relações capitalistas, culminando no liberalismo econômico na Idade Moderna, surgiu na Europa o que mais tarde seria o conceito chave para a democracia moderna, qual seja, a soberania popular. Contudo, não era o povo que fazia parte do popular no caso, e sim, uma elite privilegiada burguesa que reforçava a separação entre os governantes e o campesinato explorado e dependente politicamente. (WOOD, 2003).

A partir do desenvolvimento do comércio, da indústria moderna, bem como do mercado mundial, portanto, o capital passou a se concentrar na classe em ascensão, qual seja a burguesia, a qual ao centralizar os meios de produção, detém o domínio político exclusivo no Estado e substitui todas as liberdades pela liberdade de comércio. (MARX, ENGELS, 2008).

Assim, com a expansão da maquinaria e da divisão do trabalho, bem como do desenvolvimento do sistema capitalista, o proletário perdeu sua autonomia alienando sua força de trabalho e passou a ser explorado pelos detentores dos meios de produção. A partir de então, a história da sociedade foi marcada pela luta de classes.

A Revolução Francesa culminou na aceitação de propostas burguesas que enfim suprimiam o Antigo Regime, além da aprovação da Declaração dos Direitos do Homem e do Cidadão. Entretanto, conforme Gruppi (2000), a igualdade garantida em âmbito jurídico, não esteve em conformidade com a realidade: "Esses cidadãos todos iguais diante da lei são, na verdade, uma abstração: você operário, como cidadão é igual ao seu patrão; mas, quando você entra na fábrica, não é mais igual ao patrão, antes pelo contrário, você deixa de ser um cidadão." (GRUPPI, 2000, p. 40).

A antítese da situação posta, ou seja, a revolução segundo os ideais marxistas, ocorreria por meio da apropriação do Estado pelo proletariado, a qual se daria pela Ditadura do Proletariado, que, por sua vez, consiste na: “[...] descentralização do poder, e não sua concentração; é a desburocratização do poder, e não burocratização; é o povo que toma as armas, os trabalhadores armados. Ditadura do proletariado é a transferência para a sociedade de uma série de funções estatais." (GRUPPI, 2000, p. 50). 


\section{Teoria crítica: síntese}

No início do século XX, as tentativas de instaurar os ideais marxistas, em especial, na Alemanha, fracassaram. Ao mesmo tempo, se instauravam as bases do nazismo, formulando um quadro de barbárie. (MELLO; COSTA, 1993).

Segundo Silva (2015), a Teoria Crítica surgiu na Alemanha, nesse contexto, a partir da diligência de alguns estudiosos da filosofia.

Durante a década de 1920, os intelectuais alemães de esquerda, frustrados pelo fracasso da promessa socialista na Europa e em especial na Alemanha viram-se diante do seguinte dilema: apoiar o socialismo russo, fundado pelos bolcheviques, ou apoiar o socialismo moderado da República de Weimar. Dentre estas alternativas, pareceu mais sensato aos fundadores da Teoria Crítica seguir um terceiro caminho, inicialmente traduzido na visão dos pressupostos da própria teoria marxista. Esta deveria ser revista para que pudesse integrar-se de maneira mais efetiva a uma possível práxis revolucionária. Em seu período inicial a Escola Frankfurt dedicou-se, portanto, à pesquisa de caminhos teóricos que viabilizassem ao proletariado sua realização histórica enquanto sujeito revolucionário. (BUENO, 2003, p. 24).

O início do projeto se deu a partir dos investimentos feitos por Felix J. Weil. Max Horkheimer, Carl Grunberg, bem como Friederich Pollock, também eram membros do grupo. Juntos, eles iniciaram o Instituto de Pesquisa Social, na década de 1920, em Frankfrurt, que, mais tarde, iria contar com as pesquisas de Theodor W. Adorno, Hebert Marcuse e Erick Fromm e Walter Benjamim. (BUENO, 2003, p. 24).

Entretanto, segundo Honneth (2013), após as investigações acerca dos escritos que fundamentaram a Teoria Crítica do Instituto de Pesquisa Social, algumas limitações puderam ser identificadas na própria teoria em relação ao seu projeto pioneiro.

Conforme o autor, Max Horkheimer, Theodor W. Adorno e Hebert Marcuse elaboraram uma teoria social norteada por conceitos filosóficos e empíricos, mas que, por outro lado, apresentava algumas limitações quanto à sua metodologia, visto que necessitava de uma definição pertinente para avaliar os paradigmas sociais. Assim, dentre as teorias que no período de guerras tentaram elaborar o marxismo, a Teoria Crítica, em seu projeto original, se evidencia por se basear na composição de ideias marxistas, juntamente a uma epistemologia reconhecida no campo das ciências especiais, tendo como um de seus expoentes Max Horkheimer e como objetivo primordial a elaboração de uma teoria materialista acerca da sociedade, por meio do emprego de disciplinas metodológicas das 
ciências sociais em conjunto com as ideias do materialismo histórico e com isso, transpor o "purismo teórico" da teoria marxista. (HONNETH, 2013).

Tal empreendimento, segundo Honneth (1990), teria encontrado em Frankfurt o melhor contexto em questão de organização, financiamento, flexibilidade de que necessitaria a realização de projetos como o idealizado por Horkheimer, o qual passou a dirigir o Instituto de Investigação Social, se comprometendo a colaborar com esse projeto.

A partir de então, Horkheimer e Marcuse começaram a difundir suas ideias acerca da Teoria Crítica cuja epistemologia superava as limitações desencadeadas pelo embate entre a metafísica e o cientificismo, propondo uma filosofia histórica, uma ciência que utilizasse das contribuições de ambos os campos, ou seja, que se baseasse na filosofia como também nas ciências empíricas. Ademais, escreve o autor supracitado, naquele momento, os estudantes identificavam algumas deficiências no positivismo contemporâneo, propagando essas ideias nos artigos publicados na época. A crítica, baseada em princípios marxistas, estaria no fato de que o positivismo considerava no processo científico, apenas dimensões metodológicas, negando as questões em termos do vínculo com a realidade e com a prática. Nesse sentido: “[...] al justificar las ciencias sólo en el plano metodológico, el positivismo las desvincula tanto de la conciencia de sus propias raíces sociales como del conocimiento de sus objetivos prácticos." (HONNETH, 1990, p. 450). Assim, ao formular a crítica sobre esse modo de fazer ciência, Horkheimer nomeia-a de teoria tradicional, a qual ele em conjunto com Marcuse contrapõe com a Teoria Crítica.

Segundo Horkheimer (1937, p. 245):

A teoria em sentido tradicional, cartesiano, como a que se encontra em vigor em todas as ciências especializadas, organiza a experiência à base da formulação de questões que surgem em conexão com a reprodução da vida dentro da sociedade atual. Os sistemas das disciplinas contêm os conhecimentos de tal forma que, sob circunstâncias dadas, são aplicáveis ao maior número possível de ocasiões. A gênese social dos problemas, as situações reais, nas quais a ciência é empregada e os fins perseguidos em sua aplicação, são por ela mesma considerada exteriores. - A teoria crítica da sociedade, ao contrário, tem como objeto os homens como produtores de todas as suas formas históricas de vida. As situações efetivas, nas quais a ciência se baseia, não é para ela uma coisa dada, cujo único problema estaria na mera constatação e previsão segundo as leis da probabilidade. O que é dado não depende apenas da natureza, mas também do poder do homem sobre ela. Os objetos e a espécie de percepção, a formulação de questões e o sentido da resposta dão provas da atividade humana e do grau de seu poder.

O advento de uma nova etapa do sistema capitalista, qual seja o capitalismo financeiro, tendo como uma de suas características a difusão do imperialismo, não se 
exprimiu por meio apenas das relações econômicas, mas também, por via da cultura, da política, desencadeando transformações no âmbito social. (MELLO; COSTA, 1993).

Assim, segundo Tommaselli (2009), os idealizadores da teoria crítica, teriam buscado a partir dela, a adaptação da teoria marxista, ao novo paradigma capitalista. Ainda de acordo com o autor, "A teoria crítica tem como abordagem chave, a necessidade de uma sociedade racional, que desenvolva uma postura crítica frente à sociedade e a cultura contemporânea e, que possibilite a emancipação humana.” (TOMMASELLI, 2009, p. 12).

Para investigar as novas formas de organização da sociedade, (estas elucidadas por meio da referência marxista acerca das forças de produção impelidas no sistema capitalista), utilizando-se das orientações filosóficas como também do campo empírico, seriam necessárias as contribuições de diversas disciplinas das ciências sociais. Dessa forma, naquele momento, a principal questão formulada por Horkheimer, qual seja: “Cómo se producen los mecanismos mentales que hacen posible que la tensión entre clases sociales, empujadas al conflicto a causa e la situación económica, pueda permanecer latente?" (HORKHEIMER, 1932, p. 136 apud HONNETH, 1990, p. 452), somente seria esclarecida por meio das contribuições de disciplinas como a economia política, a psicologia social, baseada em estudos freudianos acerca do inconsciente, bem como as teorias culturais.

Para tanto, segundo Honneth (1990), o projeto contou com a colaboração de alguns estudiosos em cada enfoque dados às investigações dos fenômenos sociais. Friedrich Pollock, contribuiu com os estudos na área da economia política mediante a concepção de um Estado capitalista:

Pollock creía que tanto bajo el nacionalsocialismo como bajo el comunismo soviético se había configurado un capitalismo de economía planificada, un tipo de capitalismo en el que las autoridades planificadoras burocráticas habían suplantado el papel re-gulador del mercado." (HONNETH, 1990, p. 453).

Ademais, a Teoria Crítica passou a considerar os estudos de Sigmund Freud e de acordo com Silva (2015), foi se distanciando, lentamente, da teoria marxista. A busca das contribuições freudianas se deu, conforme o autor, a partir dos questionamentos feitos a respeito da passividade com a qual a as classes populares atuavam em relação às imposições do sistema capitalista.

Segundo Honneth (1990), na busca da compreensão sobre as razões ou motivos que conduzem à dominação de um indivíduo às novas formas de organização social, de forma passiva, somente poderia ser explicada a partir dos enfoques da psicologia sociológica, na 
qual Erich Fromm, o qual era influenciado pelos estudos de Freud, como também de Marx. Para Fromm: "[...] la integración de los individuos en el sistema de dominación capitalista se producía por medio de la formación social de su carácter psicosexual." (HONNETH, 1990, p. 453).

A teoria cultural, por sua vez, demonstrava que os indivíduos não são sujeitos passivos nesse processo descrito pelas novas formas de relação e organização sociais. Nesse novo contexto, a cultura exerce papel privilegiado:

Horkheimer únicamente entendía por «cultura» (siempre que no se tratara de obras de arte) aquel conjunto de medios y «aparatos» culturales que median entre las exigencias sociales conductuales externas y la psique del individuo, que se había convertido en un objeto manipulable. (HONNETH, 1990, p. 455 , grifos do autor)

Para Honneth (1990), todavia, o projeto investigativo formulado era reducionista, ao passo que analisava o processo histórico a partir tão somente da teoria marxista, limitando-o às questões relacionadas ao trabalho social (aos conceitos de dominação, controle por parte da cultura, bem como a passividade do indivíduo que é dominado) e nesse sentido, desconsiderando a dimensão comunicativa no desenvolvimento social.

A partir de então, os trabalhos de Horkheimer elucidavam essas concepções levadas à teoria crítica, concentrando as reflexões em torno da capacidade destrutiva da razão humana. A questão do trabalho é abordada de forma negativa desconsiderando a perspectiva emancipatória: "Por volta dos anos 40, Horkheimer já não acredita mais na possibilidade de uma revolução que conduza a sociedade a um estado de emancipação. O que ocorre segundo o autor, é o contrário, ou seja, as sociedades modernas ocidentais se aproximam mais da barbárie." (TOMMASELLI, 2009, p. 18). Tal fase da teoria crítica tem como expoente Theodor Adorno.

Adorno, por sua vez, que nesse período estava sendo influenciado pelo campo artístico, além de ser afetado pelas consequências do fascismo, tão logo passou a ter uma perspectiva descrente acerca dos ideários marxistas, criticando a racionalidade do materialismo histórico. Nesse sentido, as tendências adornianas encontravam identificação no pensamento de Horkheimer com a premissa de que: "[...] la situación totalitaria en que el mundo había caído con el auge del fascismo no podía explicarse ya por el conflicto de fuerzas productivas y relaciones de producción, sino por la dinámica interna de la formación de la conciencia humana." (HONNETH, 1990, p. 458) 
Esse processo deu origem a um novo ideário da teoria crítica que rompia com vários dos princípios do projeto original, difundido mediante a Dialética do Esclarecimento. Dentre os rompimentos, está a compreensão acerca do trabalho. Se antes o trabalho era compreendido como uma atividade emancipatória, agora ele seria responsável pelo que os autores denominaram de pensamento reificado. Para compreender esse processo, Horkheimer e Adorno desenvolvem o conceito da racionalidade instrumental, pelo qual se pode compreender que a partir do momento em que o indivíduo age sobre a natureza mediante o seu trabalho, desencadeia, por conseguinte, a repressão sobre seus instintos, bem como o início de relações dominantes. (HONNETH, 1990).

Em contrapartida, a perspectiva normativa da tendência de Horkheimer e Adorno aponta que a emancipação é alcançada ao passo que o ser humano se deixe dominar pela natureza. O problema da Dialética do Esclarecimento, escreve Honneth (2013), está no fato de limitar o processo de civilização à relação do homem com a natureza, sendo, portanto, reducionista. Nesse sentido, os autores: "[...] no tenían por qué tener dificultades para considerar retrospectivamente el proceso de civilización como una totalidad dominada por la misma racionalidad instrumental que subyace al acto de dominación de la naturaleza." (HONNETH, 1990, p. 459).

Assim, as ideias difundidas pela Dialética do Esclarecimento retrocederam em relação ao campo científico social, perdendo as conquistas alcançadas mediante à metodologia interdisciplinar, ao passo que esse novo projeto teve em grande proporção a fundamentação em princípios filosóficos. (HONNETH, 1990).

Essas limitações, conforme Honneth (1990), poderiam ser sanadas pelos autores menos influentes em relação ao Instituto quais sejam Neumann, Kirchheimer, Erich Fromm e Walter Benjamin. Entretanto, a principal deficiência da teoria crítica, na concepção de Honneth (1990), teve relação com o fato de não considerar no desenvolvimento dos fenômenos sociais, a dimensão da comunicação, da linguagem entre os indivíduos, o que fora abordado por Habermas, o qual, de acordo com autor, reelaborou a teoria crítica a partir dessa ideia.

\section{Por que pensar a educação?}

Conforme Honneth, desde o século XIX, as repúblicas democráticas pensam sobre a estrutura da escola pública, incluindo a metodologia de ensino, seu currículo e organização. O autor demonstra com isso, a existente vinculação entre o Estado e a Educação, tecendo uma 
analogia entre ambas as instituições a partir das ideias de Kant, pelas quais o Estado e Educação são inerentes e necessários um ao outro.

Para ele, mediante a esse pressuposto, difundido mais precisamente por meio de concepções modernas, alguns estudiosos conhecidos por abordarem a questão da democracia, acabaram engendrando contribuições para a educação: Rousseau, Durkheim, Dewey e Kant. Nesse sentido, a democracia é compreendida por esses autores, como um problema prático, no qual a educação teria papel privilegiado, muito embora nas discussões atuais acerca da democracia, esse tema tenha passado a exercer um papel marginal.

Por outro lado, considerando a obrigatoriedade do ensino nos estados democráticos, é mister pensar que a educação pode contribuir para a formação da democracia a partir da escolarização dos sujeitos, no sentido positivo ou negativo. Nesse sentido, Honneth se põe a refletir:

O problema da educação organizada pelo estado se encontra por demais no centro de toda ação política e toca de maneira por demais abrangente os pressupostos da consistência do estado de direito democrático para que pudesse atualmente ser separada assim sem mais nem menos do corpus de uma ciência ou filosofia da política. (HONNETH, 2013, p. 549, grifo do autor).

A educação também foi tema discutido por um dos principais idealizadores da Teoria Crítica, qual seja, Theodor Adorno. Para ele:

[...] as insuficiência dos sistemas e dos métodos da educação na atualidade suscitam uma formação cultural, ou seja, uma semiformação ou Halbbildung, que, de certo modo, provoca uma inércia e uma adaptação à dominação progressiva, das classes populares aos verdadeiros interesses do grande capital. (ADORNO, 2010 apud SILVA, 2015, p. 73, grifo do autor).

Dessa forma, Silva (2015), salienta que de acordo com o pensamento adorniano, a educação na atualidade contribui para a deficiência em relação à formação cultural, o que por sua vez, desencadeia a passividade do povo frente ao grande controle exercido pelas classes dominantes.

A partir das novas organizações sociais, engendradas pela ideologia capitalista, a formação cultural se desvinculou do que seria sua finalidade originária, conforme o pensamento de Adorno, abandonando os pressupostos emancipatórios e críticos, segundo Tommaselli (2009). O autor escreve ainda, que, a partir do capitalismo monopolista ou financeiro, a formação cultural estaria relacionada à finalidade de adaptar o indivíduo à sua realidade e não de emancipá-lo. 
Nesse contexto, de acordo com Adorno (1995) a principal finalidade da educação, deveria contemplar as necessidades políticas de uma democracia e, portanto, teria como objetivo a emancipação dos indivíduos, de forma a não desconsiderar a realidade, mas promover a conscientização sobre a mesma e a resistência à pressão da ideologia dominante.

Ademais, para Adorno, a educação deveria contribuir contra a ocorrência da barbárie, a qual é compreendida por ele da seguinte forma:

[...] estando na civilização do mais alto desenvolvimento tecnológico, as pessoas se encontrem atrasadas de um modo peculiarmente disforme em relação à sua própria civilização - e não apenas por não terem em sua arrasadora maioria experimentado a formação nos termos correspondentes, ao conceito de civilização, mas também por se encontrarem tomadas por uma agressividade primitiva, um ódio primitivo ou, na terminologia culta, um impulso de destruição, que contribui para aumentar ainda mais o perigo de que toda esta civilização venha a explodir, aliás uma tendência imanente que a caracteriza. (ADORNO, 1995, p. 155).

Nesse sentido, o autor critica a ideia de que um dos aspectos promotores do sucesso educacional é a competitividade entre os educandos, pensamento esse que para Adorno, se faz presente em grande parte dos/as educadores/as, mas que pelo contrário do que se acredita, é propulsor da barbárie. Assim, por intermédio do processo educacional, desde a primeira infância, as pessoas deveriam aprender a não violência e não a competitividade.

Adorno explica a partir de conceitos freudianos, que a autoridade exerce um grande papel na conquista da emancipação na primeira infância. Ocorre que no processo de desenvolvimento, o indivíduo se identifica com a autoridade a qual mantém contato, até que o percebe de forma não idealista, o que contribui para sua emancipação. Esse processo acaba sendo prejudicado pelo fato de que a organização da nossa sociedade contribui para a formação da heteronomia, e dessa forma, grande parte das pessoas não consegue controlar o Superego. Para o autor:

[...] a organização social em que vivemos continua sendo heterônoma, isto é, nenhuma pessoa pode existir na sociedade atual realmente conforme suas próprias determinações; enquanto isto ocorre, a sociedade forma as pessoas mediante inúmeros canais e instâncias mediadoras, de um modo tal que tudo absorvem e aceitam nos termos desta configuração heterônoma que se desviou de si mesma em sua consciência. (ADORNO, 1995, p. 181).

Assim, no processo de desenvolvimento, o indivíduo tem dificuldades de se identificar com o adulto autoritário repressor, não elaborando sua autonomia. Em sua adultícia, acaba necessitando recorrer a modelos, reproduzindo a postura autoritária repressiva com a qual teve contato anteriormente, o que conduz à menoridade. 
Adorno toma alguns pressupostos de Kant em relação ao conceito de esclarecimento. Conforme os princípios kantianos, o esclarecimento tem relação com o abandono do sujeito sobre sua menoridade, a qual, grosso modo, consiste na heteronomia. Nesse sentido, para Adorno, o enfrentamento desse problema se daria por meio da educação, porém, não aquela educação que favorece a heteronomia, a competitividade, mas a educação que propicia a resistência à menoridade, a crítica aos aparatos que exercem domínio sobre as pessoas por meio da indústria cultural, lhes transmitindo inverdades.

\section{Considerações finais}

Os ideais fundamentados na teoria marxista objetivaram, grosso modo, analisar a nova composição social, na qual instaurava-se a sociedade burguesa, com o advento do sistema capitalista. Difundiu-se, por meio das ideias de Karl Marx a compreensão de que a partir do desenvolvimento do capital, ocorreu a centralização dos meios de produção, que passou a ficar sobre domínio de uma classe dominante, qual seja, a classe burguesa. Por outro lado, destituídos da posse sobre os meios de produção, a classe operária passou a ser explorada, vendendo sua única posse, a força de trabalho, e dessa forma, sendo cada vez mais distanciada de sua liberdade e autonomia.

Além disso, as ideias marxistas compunham uma teoria do conhecimento a partir da qual compreendia-se a história como um processo dialético, ou seja, em constante transformação, no qual a ação do homem, principalmente mediante o trabalho, toma posição privilegiada.

A superação da luta de classes, sendo a tese, conforme o método dialético, ocorreria por intermédio da ditadura do proletariado (antítese), donde a classe operária tomaria o poder do Estado e por meio de um processo de modificações econômicas, culturais e políticas, instauraria a sociedade comunista (síntese).

Contudo, ao passo que surgiu uma nova configuração do sistema capitalista, a qual modificou as relações políticas, desencadeando a Primeira Guerra Mundial, os adeptos ao socialismo marxista, buscaram adaptar a Teoria Marxista, de forma que ela atendesse ao novo desenho da sociedade. Nesse sentido, Max Horkheimer, dentre outros estudantes de Filosofia na Alemanha do século XX, formularam a Teoria Crítica.

A Teoria Crítica tinha ainda suas bases filosóficas no marxismo, porém, trouxe uma grande inovação quanto a questão do método, quando propunha a fusão entre ciências naturais e as ciências sociais. 
Todavia, a barbárie se engendrava mundialmente, por meio das ideologias nazifascistas, o que contribuiu com uma revisão da própria Teoria Crítica, distanciada aos poucos do marxismo, momento no qual, possibilitou abertura à outras disciplinas que pudessem explicar a forma como a sociedade estaria se estabelecendo na época.

É a partir dessas ideias que um dos principais teóricos críticos, Teodor Adorno, formula sua concepção acerca do papel da educação, tecendo uma crítica a forma como a sociedade atual concebe a formação cultural, a qual, ao invés de promover a autonomia e emancipação, desenvolve a menoridade e a adaptação acrítica dos indivíduos à sua realidade.

Contudo, pensar no desenvolvimento de uma prática educativa que objetive a emancipação, requer pensar quais são as condições que possibilitam a concretização dessa ideia. Dada a realidade brasileira, por exemplo, é complexo pensar uma educação para a emancipação, considerando que a escola e o sistema educacional é posse de um Estado que pouco se interessa pela formulação de políticas educacionais que promovam a consciência crítica, na qual a estrutura, funcionamento, currículo e avaliação são de total controle estatal, cuja política é ainda fundamentada em concepções liberais, cuja formação cultural é deturpada de forma a legitimar a ideologia dominante.

Nesse sentido, o tabu vivido pelos/as educadores/as brasileiros se refere a como levar o esclarecimento a uma sociedade que o resiste, considerando que os/as próprios/as educadores/as muitas vezes não compartilham dos ideais de emancipação por não conseguiram transcender sua própria menoridade?

\section{REFERÊNCIAS}

ADORNO, T. Educação e emancipação. Rio de Janeiro. Paz e Terra. 1995.

BUENO, S. F. Pedagogia sem sujeito: qualidade total e neoliberalismo na educação. São Paulo: Annablume/Fapesp, 2003.

DEMO, P. Metodologia científica em ciências sociais. 3 ed. São Paulo: Atlas, 1995.

GRUPPI, L. Tudo começou com Maquiavel: as concepções de Estado em Marx, Engels, Lênin e Gramsci. 15 ed. Porto Alegre: L\&PM, 2000.

MARX, K.; ENGELS, F. Manifesto do partido comunista. Petrópolis, RJ: Vozes, 2008.

MELLO, L. I. A.; COSTA, L. C. A. História moderna e contemporânea. São Paulo: Scipione, 1993. 
HONNETH, A. La Teoría Crítica. In: GIDDENS A., TURNER J. et al. La Teoría social hoy, Madrid, 1990, p. 445-488.

HONNETH, A. Educação e esfera pública democrática: um capítulo negligenciado da filosofia política. Civitas, v. 13, n. 3, p. 544-562, 2013.

HORKHEIMER, M.; Filosofia e teoria crítica. In: BENJAMIN, W.; HORKHEIMER, M.; ADORNO, T.; HABERMAS, J. Textos Escolhidos. São Paulo: Victor Civita, 1975.

SILVA, O. V. Teoria crítica, neoliberalismo e educação: análise reflexiva da realidade educacional brasileira a partir da reforma educacional de 1990. 2015. 108 f. Dissertação (Mestrado em Educação) - Faculdade de Filosofia e Ciências, Universidade Estadual Paulista, Marília. 2015.

TOMMASELLI, G. C. G. Teoria crítica e educação. 2009. 61 f. Trabalho de Conclusão de Curso (Graduação em Ciências Sociais) - Faculdade de Filosofia e Ciências, Universidade Estadual Paulista, Marília. 2009.

TRIVIÑOS, A. N. S. Introdução à pesquisa em ciências sociais: a pesquisa qualitativa em educação. São Paulo: Atlas, 1987.

WOOD, Ellen Meiksins. Democracia contra capitalismo. São Paulo: Boitempo, 2003.

\section{Como referenciar este artigo}

FIORINI, Jessica Sampaio. Teoria marxista, teoria crítica e educação. Doxa: Rev. Bras. Psico. e Educ., Araraquara, v. 20, n. 2, p. 196-211, jul./dez., 2018. e-ISSN: 2594-8385. DOI: 10.30715/doxa.v20i2.12023

Submetido em: 01/07/2018

Aprovado em: 01/11/2018 